\title{
On the Maintenance of Power Transformer and Accessories
}

\author{
$\mathrm{Xu}$ Jun, Chen Xu, Tang Zhengran \\ Benxi Power Supply Company of National Grid Liaoning Electric Power Co., Ltd. \\ bxwl_650928@126.com
}

Keywords: Transformer; Condition-based Maintenance; Technology; Faults

\begin{abstract}
The rapid power grid construction has raised higher requirements for the safe and reliable operation of transformer so as to reduce the operational costs. Under the new maintenance model, the maintenance should be timely exercised and issues properly handled if necessary so as to ensure the implementation of condition-based maintenance strategy. It, to a large extent, can save maintenance fees and guarantee the safe and reliable operation of transformer.

As the transformer consists of iron core, coil, fuel tank, lead, tap switch and casing pipes, the following aspects should receive close attention for field maintenance.
\end{abstract}

\section{Transformer Maintenance}

(1) To examine and repair the transformer, it is necessary to expose the transformer first. Therefore, the possibility and degree of wetted insulation of the transformer is related to the atmospheric humidity and temperature, the temperature of transformer core and the duration of core exposure to the atmosphere. Therefore, it is demanding to shorten the time for exposure in air; control the temperature of iron core during lifting (equal to or higher than the air temperature; if this requirement cannot be met, the heating measures should be taken); the time for the exposure of iron core to air shall be controlled within 16 hours if the relative air humidity is no more than $65 \%$ but within 12 hours if no more tnan $75 \%$. If the iron core temperature is 3 to 5 degree centigrade higher than the surrounding air temperature, the exposure time can be extended two times longer. The exposure duration starts from the time when the transformer comes into contact with the air to the time it is sunk into oil.

(2) Preparations before Suspended Core (windlass cover): In the examination and repair of transformer, the suspended core (windlass cover) is a rigorous work; therefore, it is necessary to make full preparations and preconceive the problems that might prop up and corresponding countermeasures.

(3) The lifting can be started under the guidance of the lifting work and in accordance with the relevant regulations of the manufactory after the preparations have done.

(4) Examination of Iron Core Coil: the iron core in a running transformer gives out heat and is subject to electromagnetic vibration. Likewise, the coil sends out heat when the current passes through it and suffers from greater electromotive force impact during an external short circuit and start-stop. All these factors may give rise to abnormal conditions. Therefore, it is of prime importance to carefully examine the iron core coil when the transformer is lifted. The iron core consists of overlapped silicon steel sheet. During an examination, it is necessary (1)to observe whether the iron core is plagued by deformation or overheating and if the only touch down point is in good condition; (2) to check whether the clamping device of iron core is loose by repeatedly screwing down the nut of each bolt with the appropriate wrench. If there is any looseness, it is required to screw down immediately; (3) to check if the oil canal is smooth or whether there is sludge in the oil canal and damage or looseness to the pipping cord; (4) to check whether the ground lug of coil opening pressure ring is in good condition or deformed; open the ground lug to check the insulation between pressure ring and iron core with 2500 volts; (5) to check whether the thro-core screw and wooden support screw are tightened or whether there are anti-looseness measures. 
If the insulation between iron core and clamp is not qualified, it is necessary to check whether there is any damage to square iron insulation besides the examination of the electric impurities between the clamp and iron core and coil base and iron core. At the same time, it is also demanding to clear away the dirt accumulated on the surface and wash them with transformer oil because these dirt will impact the heat dissipation of iron core and increase the temperature of transformer iron core.

Only the external coils can be seen after the transformer is lifted up. As surface is covered by high-pressure coils, attention should be paid to the following aspects: (1) to check whether the coil has become a cross-over block, if the pipping cord has become loose and if there is a fixed assembly or displacement between the coil and iron core, wires and coil; (2) to check if each set of coil is orderly arranged and if there is uniform space; (3) to ensure clamp jackscrew is closely up against the pressure ring; however, it shall be neither too tight nor too loose; (4) to make sure there is no oil sludge on the coil surface and the smoothness of oil canal; (5) to make sure the completeness of insulating layer of coil and no discoloration, brittle rupture or breakdown defects of surface elements and observe and appraise the aging conditions.

Considering the different insulation quality, insulation can be divided into four levels: Level 1 refers to better insulation, as evidenced by the soft and elastic insulation layer, light but bright color and non-permanent deformation; Level 2 is eligible with dry and hard insulation layer, deep and dark color and trade left after being pressed by fingers; Level 3 is unreliable, dark color and tiny cracking after being pressed by fingers; Level 4 is insulation aging, as evidenced by the crisp insulation, cracking on the surface and bate pricks. The insulation layer falls off after being pressed by fingers. Such insulation layer should therefore be replaced.

(5) Lead maintenance: The lead must kept complete with good insulation. The capacitance casing pipe lead shall be well wrapped up with the white cloth tape to avoid the shunt in the lead or the internal wall of casing pipes and the burning of lead.

(6) Maintenance of Tap-switch: the transformers with voltage regulation produced in China include reactance-type and resistance-type switch. The rectance-type switch and transformer exist in the same tank while the resistance-type switch exists in an isolated tank of the transformer oil tank. The isolated tank, with its own oil chamber, respirator and gas relay, does not connect with the oil in the transformer.

(7) Maintenance of tank shell and cover: the tank shell and cover of box-type transformer constitute a sealer container. The tank shell and cover are fixed by bolts. To install high and low-pressure casing pipes, turning handle for tap switch, explosion-proof tube, expansion tank, manhole door and radiator. Many holes are opened on the tank shell and cover with oil resisting rubber jointing applied to the seal materials at the joint. Therefore, in an overhaul, it is necessary to replace all the rubber mat to avoid the oil leakage of tank shell and tank cover. From the perspective of condition-based maintenance, it is of safe and economical rationality, bringing the transformer to the next cycle of maintenance.

(8) The large-scale transformers are usually installed outdoor and subject to natural environment, such as thunderstorm, whole gale and hail. Therefore, dust usually accumulate on the surface of tank shell and at the joint, thus giving rise to the corrosion at the joint. Some transformers with poor sealing have exacerbated the dirt of the tank shell and cover due to serious oil leakage, thus wasting the transformer oil and causing fires. Therefore, it is adverse in both safety and economical efficiency. To resolve this issue, it is required to thoroughly clean the tank shell and cover, shovel the corrosion and brush the paint in the overhaul of transformer.

(9) After the core of transformer has been suspended and the residual oil in the tank shell exhausted, it is suggested to clean the oily sludge and sundries in the bottom of the oil tank. Without immediate cleaning, the oil canal might be blocked, thus causing lap discharge. When cleaning the oil tank, one should bear in mind to clean the internal wall of tank shell, remove rust and brush paint (insulating paint that won't be dissolved by the transformer oil should be used).

Through the work mentioned above, the transformer undergoing maintenance will bring back to the excellent operating state, which will guarantee the stable operation of power system. 


\section{Analysis of the Common Faults}

A research on the relevant data of online operation of transformer shows that the major cause for the faults of transformers is the reduced insulation. According to the analysis, the insulation is of prime importance to the normal operation of transformers. The following factors may have great influence on the insulation: 1) Relative Temperature. The ordinary oil-immersed transformer usually adopts the oiled paper for insulation; under such mode, the changes in temperature will be subject to various factors and influence the internal insulation, thus impacting the service life of the transformer; 2) Relative Humidity. The water content in the insulating oil in the oil-immersed transformer is another factor influencing the insulation fault of transformers. Even the slight water content in the insulation oil will also impact the internal insulation of transformer; 3) Short-circuit Current. Under the normal operation of transformer, the short circuit often occurs to the exit. Once it happens, the inner winding will be subject to mechanical deformation and displacement as the result of the excessive short-circuit current. At this time, the inner insulator of transformer will result in the rapid aging of insulation materials along with the temperature increase. Under such circumstances, the transformer fault will also become frequent.

To sum up, as transformer is regarded as the core equipment of transformer substation, its safe and stable operation is of prime importance to the electrical power system. Therefore, the maintainers should exercise daily maintenance and overhaul of the transformer. During the normal operation of transformers, it is important to carefully record each data in the work so as to provide reference for the transformer fault with the data collected. After the fault has been properly handled, the relevant personnel should summarize and analyze the causes so as to ensure the efficient and stable operation of the transformers, provide the users with quality and efficient electric power, enhance the economic benefits of enterprises and make contributions to national economic development.

\section{References}

[1] Chen Shiqing. On the Condition-based Maintenance of Power Transformer [J]. Transformer.

[2] Lu Jizhi. On the Condition-based Maintenance and Development of Electric Transmission and Transformation Equipment[J ].Yunan Electric Power.

[3] Ma Jie. Carry out Equipment Condition-based Maintenance and Ensure the Safe Operation of Power Grid[J].Sci-Tech Information Development \& Economy.

[4] China Planning Press. Collaboration for the Construction and Acceptance Standard of Installation Project of Electrical Device [M].Beijing:China Planning Press.

[5] Chemistry Standardization for Power Plant Technical Committee of Ministry of Electric Power Industry. Collaboration for the Standards of Quality and Test Method of Oil Used for Electric Power [M]. China Standard Press.

[6] Chen Shiqing. On the Condition-based Maintenance of Power Transformer [J]. Transformer.

[7] Lu Jizhi. On the Condition-based Maintenance and Development of Electric Transmission and Transformation Equipment[J ].Yunan Electric Power.

[8] Ma Jie. Carry out Equipment Condition-based Maintenance and Ensure the Safe Operation of Power Grid[J].Sci-Tech Information Development \& Economy.

[9] China Planning Press. Collaboration for the Construction and Acceptance Standard of Installation Project of Electrical Device [M].Beijing:China Planning Press.

[10] Chemistry Standardization for Power Plant Technical Committee of Ministry of Electric Power Industry. Collaboration for the Standards of Quality and Test Method of Oil Used for Electric Power [M]. China Standard Press. 